\title{
FRAGMENTE ZUM VORWORT DES VERFASSERS
}

Die vorbandenen Aufzeichningen und Notizen reichen nicbt aus, auch nur in großen Zügen den Aufbau der vom Verfasser für diesen zweiten Band angekündigien Vorrede erkennen zu lassen. Docb sei bier zusammengestellt, was sich für diese vorgemerkt fand.

Dem Namen Welcker begegnet man immer wieder, daneben wird auch Wellbausen genannt und Erman und Sethe, von eigenen Werken der Isyllos von Epidauros, die Rede "Neujabr 1900" (vgl. unten S. 523) und die Frankfurter Vorträge (unten S. 520). "Non remisi ad priora, z.B. Antig. Karyst. 275." Einzeluntersucbungen, die er nocb bätte fübren können, seien für weitere Beiträge geplant gewesen, "aber keine Zeit". Mebrfach findet sich die Klage über die "Anomalie" des Ganzen: er babe darstellen wollen, mußte aber doch immer wieder in die Untersucbung fallen, die sich nicbt babe aussondern lassen. Der Versuch der Beilagen sei gescheitert. Er beklagt auch Wiederbolungen, freilich "einzelnes mußte wiederbolt werden, in anderem Zusammenbange, weil es so und so beleuchtet". "Dubletten manchmal im Interesse des Lesers, statt nachzuscblagen." Zusammenfassend sagt er einmal binsicbtlich des ersten Bandes: "Icb muß selbst gestehen, daß die Ausarbeitung ungleich, in vielem unbefriedigend ist, Lücken und leider auch Wiederbolungen zeigt. Aber da $\beta$ ich ₹u der Umarbeitung, deren Notwendigkeit ich empfand, den Mut nicht mebr batte, wird boffentlich meinem Alter verziehen werden." Die Zitate seien ungleich, sie wollten nicht erschöpfen, sondern nur Beispiele bringen. „W as die vulgären Bücber geben, nicbt belegt, nur berausgeboben, was nützlich scbien." Weiter beißt es: ,Wenn ich die griecbischen Bücher lese und daneben, was von den arcbäologischen Entdeckungen mir vor die Augen kommt, stoße ich immer wieder auf Tatsachen, die Erwähnung forderten. Auf moderne Meinungen einzugeben babe ich keine Zeit mebr." Ferner war wobl auch für das Vorwort bestimmt die Notiz: "Es ist ein Febler, daß icb nicbt Kirchenjabre vorgefübrt babe" (vgl. dazu I 35, I) sowie die nacbstebende Bemerkung: „Allgemeine Religionsgescbicbte erst jenseits 
der Einzelreligionen, wie allgemeine Spraclwissenscbaft binter den Einzelspracben. Cbristlicbe Theologen können natürlich belfen, aber sie seben die Dinge unter dem Vorbebalte, im Christentume absolute Religion zu baben, berechtigt, weil sie für Europäer die böcbste ist." Scbließen sollte die Vor-

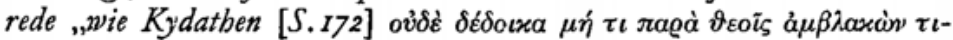

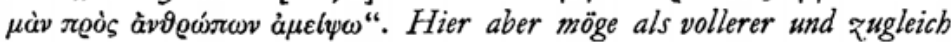
mabnender Ausklang an den Scbluß gerückt sein, was Wilamowitz ebenfalls im Vorwort aussprecben wollte:

„Der Fortschritt in unserem Wissen gescbiebt durch die Untersucbung, also die analytische Kritik der Überlieferung, die zur Feststellung einer Wabrbeit fübrt. Es bleibt analytische Untersucbung, auch wenn neue Faktoren in die Rechnung eingestellt werden; die Vermebrung des. Materials ändert das Ergebnis, nicht die Metbode. Die Syntbese nimmt die gewonnenen Einzelergebnisse zusammen und gelangt so ₹u einem Vollbilde. Sie ist unentbebrlich, rückt vieles einzelne erst in das rechte Licht und kann sagen, daß die analytische Forscbung nur Vorarbeiten für sie liefert. Aber sie reizt $z^{\prime \prime}$ neuser Forschung, und je stärker sie es tut, um so eber genügt sie nicbt mebr. Eine neuse wird nötig, und so gebt es weiter, solange Leben in der Wissenschaft ist." 